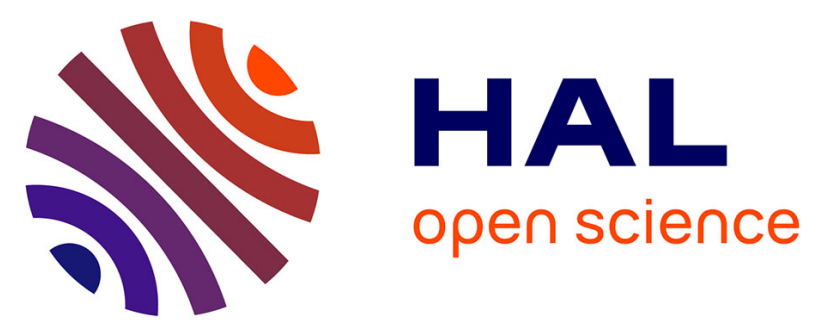

\title{
Prevalence of Listeria spp. and characterization of Listeria monocytogenes isolated from food products in Tetouan, Morocco
}

\author{
Nadia Amajoud, Alexandre Leclercq, Jose M Soriano, Hélène Bracq-Dieye, \\ Mohammed El Maadoudi, Nadia Skalli Senhaji, Ayoub Kounnoun, Alexandra \\ Moura, Marc Lecuit, Jamal El Abrini
}

\section{To cite this version:}

Nadia Amajoud, Alexandre Leclercq, Jose M Soriano, Hélène Bracq-Dieye, Mohammed El Maadoudi, et al.. Prevalence of Listeria spp. and characterization of Listeria monocytogenes isolated from food products in Tetouan, Morocco. Food Control, 2018, 84, pp.436-441. 10.1016/j.foodcont.2017.08.023 . pasteur-02326838

\section{HAL Id: pasteur-02326838}

\section{https://hal-pasteur.archives-ouvertes.fr/pasteur-02326838}

Submitted on 22 Oct 2019

HAL is a multi-disciplinary open access archive for the deposit and dissemination of scientific research documents, whether they are published or not. The documents may come from teaching and research institutions in France or abroad, or from public or private research centers.
L'archive ouverte pluridisciplinaire HAL, est destinée au dépôt et à la diffusion de documents scientifiques de niveau recherche, publiés ou non, émanant des établissements d'enseignement et de recherche français ou étrangers, des laboratoires publics ou privés.

\section{(1)(1) $(2)$}

Distributed under a Creative Commons Attribution - NonCommercial - ShareAlikel 4.0 


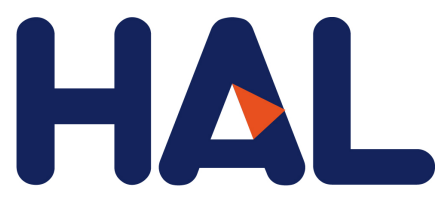

archives-ouvertes

\title{
Prevalence of Listeria spp. and characterization of Listeria monocytogenes isolated from food products in Tetouan, Morocco
}

\author{
Nadia Amajoud, Alexandre Leclercq, Jose Soriano, Hélène Bracq-Dieye, \\ Mohammed El Maadoudi, Nadia Skalli Senhaji, Ayoub Kounnoun, Alexandra \\ Moura, Marc Lecuit, Jamal Abrini
}

\section{To cite this version:}

Nadia Amajoud, Alexandre Leclercq, Jose Soriano, Hélène Bracq-Dieye, Mohammed El Maadoudi, et al.. Prevalence of Listeria spp. and characterization of Listeria monocytogenes isolated from food products in Tetouan, Morocco. Food Control, Elsevier, 2018, 84, pp.436-441. 10.1016/j.foodcont.2017.08.023 . pasteur-02326838

\section{HAL Id: pasteur-02326838}

\section{https://hal-pasteur.archives-ouvertes.fr/pasteur-02326838}

Submitted on 22 Oct 2019

HAL is a multi-disciplinary open access archive for the deposit and dissemination of scientific research documents, whether they are published or not. The documents may come from teaching and research institutions in France or abroad, or from public or private research centers.
L'archive ouverte pluridisciplinaire HAL, est destinée au dépôt et à la diffusion de documents scientifiques de niveau recherche, publiés ou non, émanant des établissements d'enseignement et de recherche français ou étrangers, des laboratoires publics ou privés.

\section{(1)(1) $(2)$}

Distributed under a Creative Commons Attribution - NonCommercial - ShareAlikel 4.0 


\title{
Prevalence of Listeria spp. and characterization of Listeria monocytogenes isolated from food products in Tetouan, Morocco
}

\author{
Nadia Amajoud ${ }^{\mathrm{a},{ }^{*}}$, Jose M. Soriano ${ }^{\mathrm{b}}$, Hélène Bracq-Dieye ${ }^{\mathrm{d}}$, Mohammed Maadoudic, \\ Ayoub Kounnoun ${ }^{a}$, Nadia Skalli Senhaji ${ }^{a}$, Alexandra Moura ${ }^{d}$, Alexandre Leclercq ${ }^{d}$, \\ Marc Lecuit ${ }^{\mathrm{d}, \mathrm{e}}$, Jamal El Abrini ${ }^{\mathrm{a}}$
}

a Laboratory of Biology and Health, Department of Biology, Faculty of Sciences of Tetouan, Abd Al Malek Essaadi University. Morocco.

${ }^{b}$ Gastrolab. Group of Food Science based in the Evidence and Experimentation Institute of Material Science. The University of Valencia Science Park. Paterna. Spain

${ }^{c}$ Regional Analysis Laboratory and Research ONSSA, Tangier, Morocco

${ }^{d}$ Infection Biology Unit and National Listeria Reference Centre, Institut Pasteur, INSERM U1117, Institut Pasteur, Paris, France.

e Division of Infectious Diseases and Tropical Medicine, Necker-Enfants Malades Descartes University Hospital, Paris, France

*Corresponding author. Laboratory of Biology and Health,Department of Biology, Faculty of Sciences of Tetouan, Abd Al Malek Essaadi University. Morocco. E-mail address: amajoud@yahoo.fr (Nadia Amajoud). 


\section{Abstract}

A total of 1096 food samples were purchased in Tetouan, North-Western of Morocco, to examine the presence of Listeria spp. Eighty (7.3\%) of the tested samples were found positive for the presence of Listeria spp., while L. monocytogenes was detected in 16 (1.5\%) samples. L. monocytogenes isolates belonged to clonal complexes CC2 (PCR serogroup IVb) and CC199 (PCR serogroup Ila) and to 8 different combined Ascl/Apal pulsed-field gel electrophoresis profiles. Core genome multilocus sequence typing (cgMLST) allowed to distinguish 12 different cgMLST types and revealed the presence of 3 clusters of closely-related isolates from different samples, suggesting the existence of common sources of contamination. Isolates showed no resistance to the reference antibiotics used for the treatment of listeriosis. This study underlines the circulation of L. monocytogenes strains of clonal complex CC2 in Morocco and highlights the importance of microbiological surveillance in order to minimize consumers' exposure to this foodborne pathogen.

Keywords: Listeria; Morocco; PCR-serogrouping; cgMLST. 


\section{Introduction}

Listeria are Gram-positive ubiquitous bacteria, widely distributed in different environments and areas (Hamon et al., 2006). There are currently seventeen species in the genus Listeria grouped into Listeria sensu stricto (L. monocytogenes, L. ivanovii, L. seeligeri, L. innocua, L. welshimeri, L. marthii) and Listeria sensu lato (L. fleischmannii, L. grayi, L. rocourtiae, L. weihenstephanensis, L. floridensis, L. aquatica, L. cornellensis, L. riparia, L. grandensis, L. booriae, L. newyorkensis) (Orsi \& Wiedmann, 2016). Among these species, L. monocytogenes is the causative agent of listeriosis, one of the most severe foodborne infections (Maertens de Noordhout et al., 2014). L. monocytogenes can resist disinfectants, form biofilms and survive or multiply under extreme physicochemical characteristics, such as dry environments, different temperatures, a wide range of $\mathrm{pH}$ and high salt concentrations. All these conditions promote the survival and proliferation of $L$. monocytogenes in a large variety of food matrices including unpasteurized dairy products, meat products, seafood, vegetables, and in food industry environments. The contamination of food products with this pathogen can occur during production, packaging, transport, and storage (Carpentier \& Cerf, 2011). Human listeriosis can manifest as septicemia, meningoencephalitis, abortion or neonatal infection with high case fatality rate $(20 \mathrm{e} 30 \%)$ even in the absence of resistance to reference antibiotic treatment (Charlier et al., 2017; Morvan et al., 2010). In Morocco, the incidence of human listeriosis remains unknown due to the absence of epidemiological surveillance (Cohen et al., 2006; Maertens de Noordhout et al., 2014), and so far only one case of a neonatal listeriosis has been reported (Benabdejlil et al., 2015; Benomar et al., 2000). Despite the lack of surveillance for Listeria infections in Morocco, several studies reporting the prevalence of $L$. monocytogenes in food have been performed in the center of the country to estimate consumers' exposure to this pathogen. In Casablanca, for instance, $L$. monocytogenes was present in $14.4 \%$ of red meat products collected in 1998 (Kriem et al., 1998), absent in 156 red meat and offal samples collected between 2002 and 2004 (Cohen et al., 2006), and present in $2.3 \%$ of 426 poultry and red meat samples collected in 2008 (Ennaji et al., 2008). A study in the city of Rabat showed increasing prevalence of $L$. monocytogenes in various foodstuffs ranging from $0.8 \%$ in 2009 to $4.1 \%$ in 2011, with the highest prevalence (13.8\%) in poultry products in 2010 (El Habib et al., 2014). Another study has reported a prevalence of $L$. monocytogenes of $3.7 \%$ in chicken meat samples collected in Rabat in 2011e2012 (Khallaf et al., 2016). In the Kenitra region, L. monocytogenes was detected in $0.8 \%$ 
of raw milk samples (Hadrya et al., 2012), whereas in the region of Fez, the prevalence of $L$. monocytogenes was 5.9\% in raw milk and traditional dairy products (El Marnissi et al., 2013). Nevertheless, the prevalence of $L$. monocytogenes in food items in Northern Morocco remains unknown. Thus, the aims of this study were: i) to evaluate the presence of $L$. monocytogenes and other Listeria spp. in different food matrices collected in Tetouan (North-Western of Morocco), ii) to characterize the antibiotic susceptibility profiles of $L$. monocytogenes isolates, and iii) to type L. monocytogenes isolates by PCR serogrouping, pulsed field gel electrophoresis (PFGE), multilocus sequence typing (MLST) and core genome MLST (cgMLST). 


\section{Materials and methods}

\subsection{Sample collection and bacteria isolation}

A total of 1096 food samples, including dairy products $(n=404)$, bovine meat products $(n=258)$, pastry ( $n=162)$, salads ( $n=143)$, poultry meat products $(n=103)$, chickpea flour cooked with eggs sold in the street $(n=20)$ and mayonnaises $(n=6)$, were collected from January 2009 to August 2015. The samples were obtained from different food outlets in Tetouan (NorthWestern of Morocco). All samples were immediately transported to the laboratory at $5 \pm 3{ }^{\circ} \mathrm{C}$ and were microbiologically examined within 1-2 $\mathrm{h}$ after sampling. Isolation and identification of Listeria spp. were performed according to the official method for the detection of $L$. monocytogenes (ISO, 1996). Biochemical identification was performed using the API- Listeria system (bioMérieux, Marcy l'Etoile, France) (Bille et al., 1992). Listeria strains were stored at $80^{\circ} \mathrm{C}$ in Brain Heart Infusion (Biokar, Beauvais, France) with $20 \%$ glycerol until further use.

\subsection{PCR serogrouping}

PCR serogrouping was determined by multiplex PCR targeting Imo0737, ORF2819, ORF2110, Imo1118, and prs gene regions, using primers and conditions as previously described by Doumith et al. (2004). PCR products were resolved on a $2 \%$ agarose gel containing $0.5 \mathrm{mg} / \mathrm{ml}$ of ethidium bromide (Eurobio, Courtaboeuf, France) and documented using the Bio-Rad Gel Doc 2000 ${ }^{\text {TM }}$ imaging system (Bio-Rad Laboratories, Milan, Italy). Electrophoresis profiles were interpreted according to Doumith et al. (2004) and Leclercq et al. (2011).

\subsection{PFGE Ascl/Apal typing}

L. monocytogenes PFGE fingerprints were obtained with the restriction enzymes Ascl (New England BioLabs, Massachusetts, Ipswich, USA) and Apal (MBI Fermentas, Burlington, Canada), as previously described by Graves \& Swaminathan (2001) and Martin et al. (2006). The combined Ascl/Apal PFGE pulsotypes were analyzed using BioNumerics software version 6.6 (Applied Maths, Kortrijk, Belgium). Bands automatically assigned by the computer were checked visually and corrected manually when necessary. Cluster analysis of the individual or combined PFGE pulsotypes was performed using the unweighted pair group method with average linkage (UPGMA) method. The similarities of the banding patterns were estimated based on Dice's coefficient (Dice, 1945). The discriminatory power was determined by 
calculating the discrimination index (D) based on Simpson's index of diversity (Hunter Gaston, 1988). Two PFGE patterns were considered to be similar if they differed by less than two bands (Martin et al., 2006).

\subsection{MLST and cgMLST molecular typing}

L. monocytogenes genome sequences were obtained after DNA extraction (DNeasy Blood Tissue kit, Qiagen, Denmark), library preparation (Nextera XT DNA Sample kit, Illumina, California, USA) and sequencing using NextSeq 500 (2 x 150 bp) platform (Illumina, California, USA), according to the manufacturer's protocol. Draft assemblies were obtained using CLC Assembly Cell 4.3.0. (Qiagen, Hilden, Germany), as previously described (Moura et al., 2017). MLST and cgMLST profiles were obtained from genomic data as described previously (Moura et al., 2016; Ragon et al., 2008). cgMLST types were defined using the profile similarity cut-off of $99.6 \%$ (i.e. isolates sharing 7 or less allelic differences on 1748 alleles were considered the same type), as previously described (Moura et al., 2016). cgMLST clusters were defined as groups of isolates sharing the same cgMLST type.

\subsection{Antimicrobial susceptibility testing}

L. monocytogenes isolates were tested for their antimicrobial susceptibility using the agar disc diffusion method following the guidelines of the French committee on antimicrobial susceptibility testing (French Society of Microbiology [SFM], 2016; Morvan et al., 2010). Inoculum concentration was standardized by turbidimetry (Densimat photometer, bioMérieux). Mueller-Hinton agar plates (bioRad, Marne-la-Coquette, France) were inoculated with $1.0-2.0 \times 10^{8} \mathrm{cfu} / \mathrm{ml}$ and incubated at $35^{\circ} \mathrm{C}$ for $24 \mathrm{~h}$. The following discs (Oxoid Ltd., Hampshire, United Kingdom) of antimicrobial agents were used in this study: amikacin (30 mg), amoxicillin (25 mg), ampicillin (10 mg), cefotaxime (30 mg), chloramphenicol (30 mg), ciprofloxacin (5 mg), clindamycin (2 mg), erythromycin (15 mg), fosfomycin (50 mg), fusidic acid (10 mg), gentamicin (15 mg), imipenem (10 mg), kanamycin (30 mg), levofloxacin (5 mg), lincomycin (15 mg), moxifloxacin (5 mg), nalidixic acid (30 mg), penicillin $\mathrm{G}(6 \mathrm{mg})$, rifampicin (30 mg), streptomycin (10 mg), sulfametoxazole (200 mg), tetracycline (30 mg), trimethoprim (5 mg), tobramycin (30 mg), and vancomycin (30 mg). The diameters of growth inhibition zones were measured with Scan 4000 (Interscience, Saint Nom, France). Strains were classified as susceptible, intermediately resistant (reduced susceptibility), or resistant by using the 
breakpoints recommended by the French Committee on antimicrobial susceptibility testing (French Society of Microbiology, 2016). Streptococcus pneumoniae ATCC 49619 and Escherichia coli ATCC 25922 were used as the quality control strains (French Society of Microbiology, 2016).

\section{Results}

\subsection{Prevalence of Listeria spp. and L. monocytogenes}

The distributions of the different Listeria species per type of sample are presented in Table 1. Listeria spp. isolates were detected in 80 out of 1096 (7.3\%) food products. These belonged to L. innocua (57 samples; 5.2\%), L. monocytogenes (16 samples; 1.5\%), L. welshimeri (4 samples; 0.4\%) and L. seeligeri (3 samples; 0.3\%) (Table 1). None of the samples were simultaneously contaminated by different Listeria species. The sampling plan used did not allow to clarify the prevalence of Listeria per type of food per year. Among the 80 positive samples, the highest prevalence of Listeria spp. were found in mayonnaise (33.3\%) and chickpea flour cooked with eggs sold in the street (25\%), followed by poultry meat (14.6\%) and bovine meat (12.8\%) products. Lower prevalence was observed in pastries (4.9\%), dairy products (3.2\%) and salads (2.8\%). L. monocytogenes was predominantly isolated from mayonnaise (16.7\%), pastries (3.1\%) and bovine meat products (2.7\%) (especially mortadella), and to a lesser extent in dairy products $(0.7 \%)$ (raw milk, traditional whey) (Tables 1 and 2).

\subsection{Molecular typing}

L. monocytogenes isolates ( $n=16)$ belonged mainly to PCR serogroup IVb (87.5\%) and only two isolates from raw milk belonged to PCR serogroup Ila (12.5\%). All L. innocua, L. welshimeri and L. seeligeri isolates belonged to PCR serotype $L$, which is the characteristic serogroup of other species than L. monocytogenes. PFGE subtyping of L. monocytogenes isolates showed 8 different PFGE combined Ascl/Apal types (Fig. 1), with three different PFGE clusters (named I to III). L. monocytogenes isolates were assigned to MLST clonal complexes CC2 ( $n=14 ; 87.5 \%)$ and CC199 ( $n=2 ; 12.5 \%)$. Genome-based typing revealed 12 different cgMLST types and 3 clusters of isolates sharing the same cgMLST type (CT2833, CT2841 and CT2002) (Table 2, Fig. 2).

\subsection{Antimicrobial resistance}

L. monocytogenes isolates showed natural resistance to cefotaxime, sulfonamide, nalidixic acid, fosfomycine and lincosamide. Two isolates (CLIP 2016/00835 and CLIP 
isolated from rawmilk) were resistant to tetracycline, due to the presence of tetM gene as revealed by genome analysis (data not shown). Resistance to penicillin G, chloramphenicol, rifampicin, streptomycin, vancomycin, fusidic acid, trimethoprim, levofloxacin, moxifloxacin, ciprofloxacin, erythromycin, amikacin, kanamycin, amoxicillin, ampicillin, gentamicin, imipenem and tobramycin was not observed (data not shown).

\section{Discussion}

This study focused on the detection and characterization of food-associated $L$. monocytogenes isolated in the North region of Morocco, in order to evaluate the burden of this pathogen in different food products. Overall, Listeria spp. were detected in $7.3 \%$ samples, being L. innocua $(5.2 \%)$ the most prevalent species, followed by L. monocytogenes $(1.5 \%)$. Nevertheless, one cannot exclude that the presence of L. innocua in the samples analyzed could inhibit the growth of L. monocytogenes initially present in the samples, resulting in falsenegative detection of $L$. monocytogenes (Carvalheira et al., 2010). Prevalence values of $L$. monocytogenes previously reported for other regions of Morocco (Ennaji et al., 2008; Hadrya et al., 2012) were in agreement with those found in the present study, but were different from those reported in others studies (Cohen et al., 2006; El Habib et al., 2014; Khallaf et al., 2016). In this study, all L. monocytogenes found in bovine meat products were recovered from mortadella. The prevalence of L. monocytogenes in mortadella (7.0\% among the 100 mortadella samples analyzed) was similar ( $p=0.6, \chi^{2}$ test) to the one reported in Egypt (Reda et al., 2016). Furthermore, several studies that examined the prevalence of $L$. monocytogenes in food (except for mayonnaise) from different Mediterranean countries reported higher prevalence values compared to our results: 5.8\% in raw milk (Boubendir et al., 2011); 14.5\% in salad samples (Effimia, 2015), $45.0 \%$ in poultry meat (El Mali et al., 2015) and $10.0 \%$ in pastries (Di Pinto et al., 2010). The differences in the prevalence of $L$. monocytogenes could be attributed to the geographical differences, sampling strategy, hygienic conditions and microbiological analysis methods. Reference treatment for listeriosis is based on the administration of a synergistic combination of aminopenicillin (ampicillin or amoxicillin) with or without gentamicin. For patients allergic to those antibiotics, trimethoprimsulfamethoxazole is recommended as alternative treatment (Hof, 2004). L. monocytogenes isolated during our study showed no resistance to the reference treatment antibiotics. These 
results were in agreement with those reported in previous studies (Charlier et al., 2017; Morvan et al., 2010). L. monocytogenes isolates belonged mostly to PCR serogroup IVb (87.5\%), belonging to phylogenetic lineage I. Isolates from lineage I have been reported as overrepresented among human isolates, while those from lineage II are overrepresented among food isolates (Maury et al., 2016). PCR serogroup IVb has been associated to the majority of clinical strains causing severe human infections (Maury et al., 2016). Moreover, during 2010-2012, the majority of deaths in Europe were linked to the two most common PCR serogroups Ila and IVb (ECDC, 2015). In the present study, the strains belonging to the first PFGE cluster (I) corresponded to L. monocytogenes isolates of PCR serogroup IVb isolated from mortadella, pastries, traditional whey, and mayonnaise collected from urban areas (Fig. 1). All strains belonging to the second PFGE cluster (II) were isolates of PCR serogroup Ila from raw milk in a rural area, where livestock production is artisanal. The third PFGE cluster (III) comprised of isolates of PCR serogroup IVb, isolated from pastries, sampled in 2012 in the same site, as in cluster (I), and from two street vendors (I-1 and I-2), located in the ancient city, where the hygienic conditions are unfavorable. In addition, it is noteworthy that these last street vendors bought their pastries from the same producer. L. monocytogenes isolates belonged to MLST clonal complexes CC2 and CC199. Maury et al. (2016) have shown that CC2 is one of the clonal complexes significantly associated with clinical isolates in France and specifically with materno-neonatal infections. Moreover, Chenal-Francisque et al. (2011) have shown that the frequent clone CC2 was found in more than 30 countries and was globally distributed. The circulation of this hypervirulent clonal complex CC2 highlights the importance for epidemiological surveillance of listeriosis, especially the maternal-neonatal forms of the disease (Leclercq et al., 2014; Maertens de Noordhout et al., 2014). Genome-based typing allowed to detect three clusters of $L$. monocytogenes isolates sharing the same cgMLST type (Fig. 2), suggesting the existence of common contamination sources. СT2833 cluster was associated with pastry from the same place of sampling (street vendors) where the hygienic conditions were likely unfavorable, and around the same period, consistent with the suspicion of a possible cross-contamination with other sold foods, such as traditional milk products, a contamination in the production environment and/or in the raw materials used to produce pastry. CT2841 cluster was associated with mortadella imported from Spain which was grated for the preparation of sandwiches and with pastry from a different place and period. Mortadella of this cgMLST cluster were sampled from the same vendor and around the same 
period, also in favor of a contamination due to a resident strain in the environment or in the raw materials used to produce this product. Isolates from cluster CT2002, as described for PFGE cluster (II), were originated from raw milk sold by local farmers on a local weekly market in a rural area, where livestock production is artisanal, which could involve animal contamination or poor hygiene during milking.

\section{Conclusion}

Listeria spp. were detected in different types of products from North of Morocco. L. monocytogenes isolates belonged primarily to PCR serogroups IVb and IIa and MLST clonal complexes CC2 and CC199. cgMLST analysis allowed to detect clusters of isolates likely sharing common sources of contamination. The current study was the first one to characterize $L$. monocytogenes strains from Morocco at the genomic level. Due to the lack a record of listeriosis cases and associated strains in Morocco, the public health impact of these results remains to be elucidated. This study highlights the importance of monitoring the dissemination of this pathogen in North Morocco and of reducing the exposition of the population, especially pregnant women, to L. monocytogenes.

\section{Acknowledgements}

This work was supported by the Regional Environmental Laboratory, of the Urban Community of Tetouan, Morocco, by The Valencia University (Preventive Medicine and Public Health, Food Sciences, Toxicology and Forensic, Medicine Department), by Regional Analysis Laboratory and Research ONSSA, Tangier, Morocco and by Institut Pasteur, Paris, France. The authors declared no conflict of interests. 


\section{References}

Benabdejlil, Y., Chergi, M., Kouach, J., Massaoui, D., Dehayni, M. (2015). Listeriosis in pregnant women in Morocco: A case report. Journal of Gynecology and Obstetrics, 3(1), $18 \mathrm{e} 20$.

Benomar, S., Nejjari, N., Lahbabi, M. S. (2000). Neonatal Listeria infection is very rare in Morocco. Archives de Pediatrie, 7(4), 428.

Bille, J., Catimel, B., Bannerman, E., Jacquet, C., Yersin, M. N., Caniaux, I., et al. (1992). API Listeria, a new and promising one-day system to identify Listeria isolates. Applied and Environmental Microbiology, 58(6), $1857 \mathrm{e} 1860$.

Boubendir, A., Mostakim, H. M., El Abed, S., Ibnsouda Koraichi, S. (2011). Incidence de Listeria spp. et autres bactéries psychrotrophes dans le lait cru bovin dans le Nord Est Algérien. Revue de Médecine Véterinaire, 162(5), 265e269.

Carpentier, B., Cerf, O. (2011). Persistence of Listeria monocytogenes in food industry equipment and premises. International Journal of Food Microbiology, 145(1), $1 \mathrm{e} 8$.

Carvalheira, A., Eusebio, C., Silva, J., Gibbs, P., Teixeira, P. (2010). Influence of Listeria innocua on the growth of Listeria monocytogenes. Food Control, 21(11), 1492e1496.

Charlier, C., Perrodeau, E., Leclercq, A., Cazenave, B., Pilmis, B., Henry, B., et al. (2017). Clinical features and prognostic factors of listeriosis: The MONALISA national prospective cohort study. The Lancet Infectious Disease, 17(5), 510e519.

Chenal-Francisque, V., Lopez, J., Cantinelli, T., Caro, V., Tran, C., Leclercq, A., et al. (2011). Worlwide distribution of major clones of Listeria monocytogenes. Emerging Infectious Disease, 17(6), 1110e1112.

Cohen, N., Ennaji, H., Hassar, M., Karib, H. (2006). The bacterial quality of red meat and offal in Casablanca (Morocco). Molecular Nutrition and Food Research, 50(6), 557e562.

Di Pinto, A. N. L., Montemurro, F., Bonerba, E., Tantillo, G. (2010). Occurence of Listeria monocytogenes in readyto-eat foods from supermarkets in Southern Italy. The New Microbiologica, 33, 249e252.

Dice, L. R. (1945). Measures of the amount of ecological association between species. Ecology, 26, $297 e 302$.

Doumith, M., Buchrieser, C., Glaser, P., Jacquet, C., Martin, P. (2004). Differentiation of the major Listeria monocytogenes serovars by multiplex PCR. Journal of Clinical Microbiology, 42(8), 3819e3822.

Effimia, E. (2015). Prevalence of Listeria monocytogenes and Salmonella spp. In ready-to-eat foods in Kefalonia, Greece. Journal of Bacteriology Parasitology, 6, 1 e8.

El Habib, F., Ennaji, M., El Ouardi, A., Senouci, S. (2014). Listeria monocytogenes in food matrix: Frequency and effect of antagonist microbial. Pakistan Journal of Nutrition, 13(3), 141e145.

El Mali, M., Can, H. Y., Yaman, H. (2015). Prevalence of Listeria monocytogenes in poultry meat. Journal of Food Science and Technology, 35, 672e675.

El Marnissi, B., Benani, L., Cohen, N., El Ouali Lalami, A., Belkhou, R. (2013). Presence of Listeria monocytogenes in raw milk and traditional dairy products marketed in the north-central region of Morocco. African Journal of Food Science, 7, 87e91.

Ennaji, H., Timinouni, M., Ennaji, M. M., Hassar, M., Cohen, N. (2008). Characterization and antibiotic susceptibility of Listeria monocytogenes isolated from poultry and red meat in Morocco. Infection and Drug Resistance, 1, 45e50.

European Centre for Disease Prevention and Control (ECDC). (2015). The European center for disease prevention and control, surveillance report of seven priority food and waterborne diseases in the EU/EEA 2010-2012. Stockholm, Sweden: ECDC.

French Society of Microbiology (SFM). (2016). Comité de l'antibiogramme de la Société Française de Microbiologie. Recommandations 2016 version 1, Paris, France.

Graves, L. M., Swaminathan, B. (2001). PulseNet standardized protocol for subtyping Listeria monocytogenes by macrorestriction and pulsed-field gel electrophoresis. International Journal of Food Microbiology, 65(1e2), $55 \mathrm{e} 62$.

Hadrya, F., Elouardi, A., Benali, D., Hami, H., Soulaymani, A., Senouci, S. (2012). Bacterial quality of informally marketed raw milk in Kenitra city, Morocco. Pakistan Journal of Nutrition, 11(8), 662e669.

Hamon, M., Bierne, H., Cossart, P. (2006). Listeria monocytogenes: A multifaceted model. Nature Reviews Microbiology, 4(6), 423e434.

Hof, H. (2004). An update on the medical management of listeriosis. Expert Opinion on Pharmacotherapy, 5(8), 1727 e1735.

Hunter, P. R., Gaston, M. A. (1988). Numerical index of the discriminatory ability of typing systems: An application of Simpson's index of diversity. Journal of Clinical Microbiology, 26(11), 2465e2466. 
International Organization for Standardization (ISO). (1996). In International organization for standardization (Ed.), ISO 11290e11291: Food Microbiology- Horizontal methods for the detection and enumeration of Listeria monocytogenes - Part1: Method of research. Geneva, Switzerland.

Khallaf, M., Ameur, N., Boraam, F., Senouci, S., Ennaji, M. M. (2016). Prevalence of Listeria monocytogenes isolated from chicken meat marketed in Rabat, Morocco. International Journal of Innovation Science and Research, 22(1), 8e13.

Kriem, M. R., El Marrakchi, A., Hamama, A. (1998). Prevalence of Listeria spp. on a variety of meat products in Morocco. M.A.N Microbiologie, Aliments, Nutrition, 16(3), $179 \mathrm{e} 187$.

Leclercq, A., Charlier, C., Lecuit, M. (2014). Global burden of listeriosis: The tip of the iceberg. The Lancet Infectious Disease, 14(11), 1027 e1028.

Leclercq, A., Chenal-Francisque, V., Dieye, H., Cantinelli, T., Drali, R., Brisse, S., et al. (2011). Characterization of the novel Listeria monocytogenes PCR serogrouping profile IVb-v1. International Journal of Food Microbiology, 147(1), 74e77.

Maertens de Noordhout, C., Devleesschauwer, B., Angulo, F. J., Verbeke, G., Haagsma, J., Kirk, M., et al. (2014). The global burden of listeriosis: A systematic review and meta-analysis. The Lancet Infectious Disease, 14(11), 1073e1082.

Martin, P., Jacquet, C., Goulet, V., Vaillant, V., De Valk, H., \& Participants in the PulseNet Europe Feasibility Study. (2006). Pulsed-field gel electrophoresis of Listeria monocytogenes strains: The PulseNet Europe feasibility study. Foodborne Pathogens and Disease, 3(3), 303e308.

Maury, M. M., Tsai, Y. H., Charlier, C., Touchon, M., Chenal-Francisque, V., Leclercq, A., et al. (2016). Uncovering Listeria monocytogenes hypervirulence by harnessing its biodiversity. Nature Genetics, 48(3), 308e313.

Morvan, A., Moubareck, C., Leclercq, A., Herve-Bazin, M., Bremont, S., Lecuit, M., et al. (2010). Antimicrobial resistance of Listeria monocytogenes strains isolated from humans in France. Antimicrobial Agents and Chemotherapy, 54(6), 2728e2731.

Moura, A., Criscuolo, A., Pouseele, H., Maury, M. M., Leclercq, A., Tarr, C., et al. (2016). Whole genome-based population biology and epidemiological surveillance of Listeria monocytogenes. Nature Microbiology, 2 , 16185.

Moura, A., Tourdjman, M., Leclercq, A., Hamelin, E., Laurent, E., Fredriksen, N., et al. (2017). Real-time wholegenome sequencing for surveillance of Listeria monocytogenes, France. Emerging Infectious Disease, 23(9), $1462 \mathrm{e} 1470$.

Orsi, R. H., Wiedmann, M. (2016). Characteristics and distribution of Listeria spp., including Listeria species newly described since 2009. Applied Microbiology and Biotechnology, 100(12), 5273e5287.

Ragon, M., Wirth, T., Hollandt, F., Lavenir, R., Lecuit, M., Le Monnier, A., et al. (2008). A new perspective on Listeria monocytogenes evolution. PLoS Pathogens, 4(9), e1000146.

Reda, W. W., Abdel-Moein, K., Hegazi, A., Mohamed, Y., Abdel-Razik, K. (2016). Listeria monocytogenes: An emerging food-borne pathogen and its public healthimplications. The Journal of Infection in Developing Countries, 10(2), $149 \mathrm{e} 154$. 
Table 1. Prevalence and biochemical identification of Listeria sp. in food samples in Tetouan (NW of Morocco) from 2009 to 2015.

\begin{tabular}{|c|c|c|c|c|c|c|}
\hline Type of sample & $\begin{array}{c}\text { No. samples } \\
\text { analyzed }\end{array}$ & $\begin{array}{c}\text { No. Listeria- } \\
\text { positive } \\
\text { samples (\%) }\end{array}$ & $\begin{array}{c}\text { L. innocua } \\
(\%)\end{array}$ & L. monocytogenes (\%) & L. welshimeri (\%) & L. seeligeri $(\%)$ \\
\hline Dairy products & 404 & $13(3.2)$ & $6(46.2)$ & $3(23.1)$ & $3(23.1)$ & $1(7.7)$ \\
\hline Meat products & 258 & $33(12.8)$ & $24(72.7)$ & $7(21.2)$ & $0(0)$ & $2(6.1)$ \\
\hline Egg products & 103 & $15(14.6)$ & $14(93.3)$ & $0(0)$ & $1(6.7)$ & $0(0)$ \\
\hline Salads & 149 & $6(4.0)$ & $5(83.3)$ & $1(16.7)$ & $0(0)$ & $0(0)$ \\
\hline $\begin{array}{l}\text { Chickpea flour cooked wit } \\
\text { eggs sold in the street }\end{array}$ & 20 & $5(25.0)$ & $5(100)$ & $0(0)$ & $0(0)$ & $0(00)$ \\
\hline Total & 1,096 & $80(7.3)$ & $57(71.3)$ & $16(20)$ & $4(5)$ & $3(3.8)$ \\
\hline
\end{tabular}


Table 2. Listeria monocytogenes isolated in food samples in Tetouan (NW of Morocco) from 2009 to 2015.

\begin{tabular}{|c|c|c|c|c|c|c|c|c|c|}
\hline CLIP Number ${ }^{a}$ & $\begin{array}{c}\text { Original } \\
\text { laboratory } \\
\text { number }\end{array}$ & Sample & $\begin{array}{c}\text { Sampling } \\
\text { date }\end{array}$ & $\begin{array}{c}\text { Sampling } \\
\text { anonymized } \\
\text { origin - Street } \\
\text { vendor }\end{array}$ & $\begin{array}{c}\text { Phylogenetic } \\
\text { lineage }\end{array}$ & $\begin{array}{c}\text { PCR } \\
\text { serogroup }^{b}\end{array}$ & $\begin{array}{c}\text { MLST } \\
\text { Clonal } \\
\text { Complex }^{d}\end{array}$ & $\begin{array}{c}\text { PFGE } \\
\text { Ascl/Apal } \\
\text { Cluster }^{c}\end{array}$ & $\begin{array}{l}\text { cgMLST } \\
\text { type }^{d}\end{array}$ \\
\hline 2016/00804 & $18 \mathrm{~lm}$ & Traditional whey & $28 / 04 / 2009$ & G & 1 & $\mathrm{IVb}$ & $\mathrm{CC} 2$ & 1 & CT2839 \\
\hline 2016/00806 & 1Pal & Mayonnaise & 01/07/2009 & $\mathrm{H}$ & 1 & $\mathrm{IVb}$ & $\mathrm{CC} 2$ & 1 & CT2843 \\
\hline 2016/00835 & Sara1 & Raw milk & 05/01/2011 & $\mathrm{J}-1$ & II & Ila & CC199 & II & CT2002 \\
\hline 2016/00836 & Sara2 & Raw milk & 05/01/2011 & $\mathrm{J}-2$ & II & Ila & CC199 & II & CT2002 \\
\hline 2016/00851 & $4 P$ & Pastry & 01/05/2012 & I-1 & I & $\mathrm{IVb}$ & $\mathrm{CC} 2$ & III & CT2840 \\
\hline 2016/00852 & $7 \mathrm{MF}$ & Pastry & 08/05/2012 & $1-2$ & 1 & $\mathrm{IVb}$ & $\mathrm{CC} 2$ & III & CT2834 \\
\hline 2016/00853 & $3 P$ & Pastry & 01/05/2012 & I-1 & 1 & $\mathrm{IVb}$ & $\mathrm{CC} 2$ & 1 & CT2833 \\
\hline 2016/00854 & $6 \mathrm{MF}$ & Pastry & 08/05/2012 & $1-2$ & 1 & $\mathrm{IVb}$ & $\mathrm{CC} 2$ & III & CT2833 \\
\hline $2016 / 00875^{f}$ & $100 / 1$ & Mortadella & $01 / 07 / 2013$ & $E-3$ & 1 & $\mathrm{IVb}$ & $\mathrm{CC} 2$ & I & CT2841 \\
\hline 2016/00876 & $66 / 11$ & Mortadella & 03/06/2013 & $A-4$ & 1 & $\mathrm{IVb}$ & $\mathrm{CC} 2$ & 1 & CT2838 \\
\hline 2016/00877 & 735 & Mortadella & 08/06/2013 & B & 1 & $\mathrm{IVb}$ & $\mathrm{CC} 2$ & I & CT2835 \\
\hline 2016/00878 & $93 / 2$ & Mortadella & $27 / 06 / 2013$ & $C-5$ & 1 & $\mathrm{IVb}$ & $\mathrm{CC} 2$ & 1 & CT2836 \\
\hline 2016/00879 & $69 / 1$ & Mortadella & 06/06/2013 & D-4 & I & $\mathrm{IVb}$ & $\mathrm{CC} 2$ & 1 & CT2842 \\
\hline $2016 / 00880$ & $93 / 1$ & Mortadella & $27 / 06 / 2013$ & $C-5$ & 1 & $\mathrm{IVb}$ & CC2 & I & CT2837 \\
\hline
\end{tabular}


$2016 / 00882^{f}$

$100 / 2$

Mortadella

01/07/2013

E-3

09/06/2015

F

IVb

CC2

CT2841

2016/00886

E4BMH

Pastry

IVb

CC2

CT2841

a, CLIP: Collection Listeria Institut Pasteur

b, according to Doumith et al. (2004)

c according to Graves and Swaminathan (2001)

d, according to Moura et al. (2016)

e, according to Ragon et al. (2008)

f, same sample 


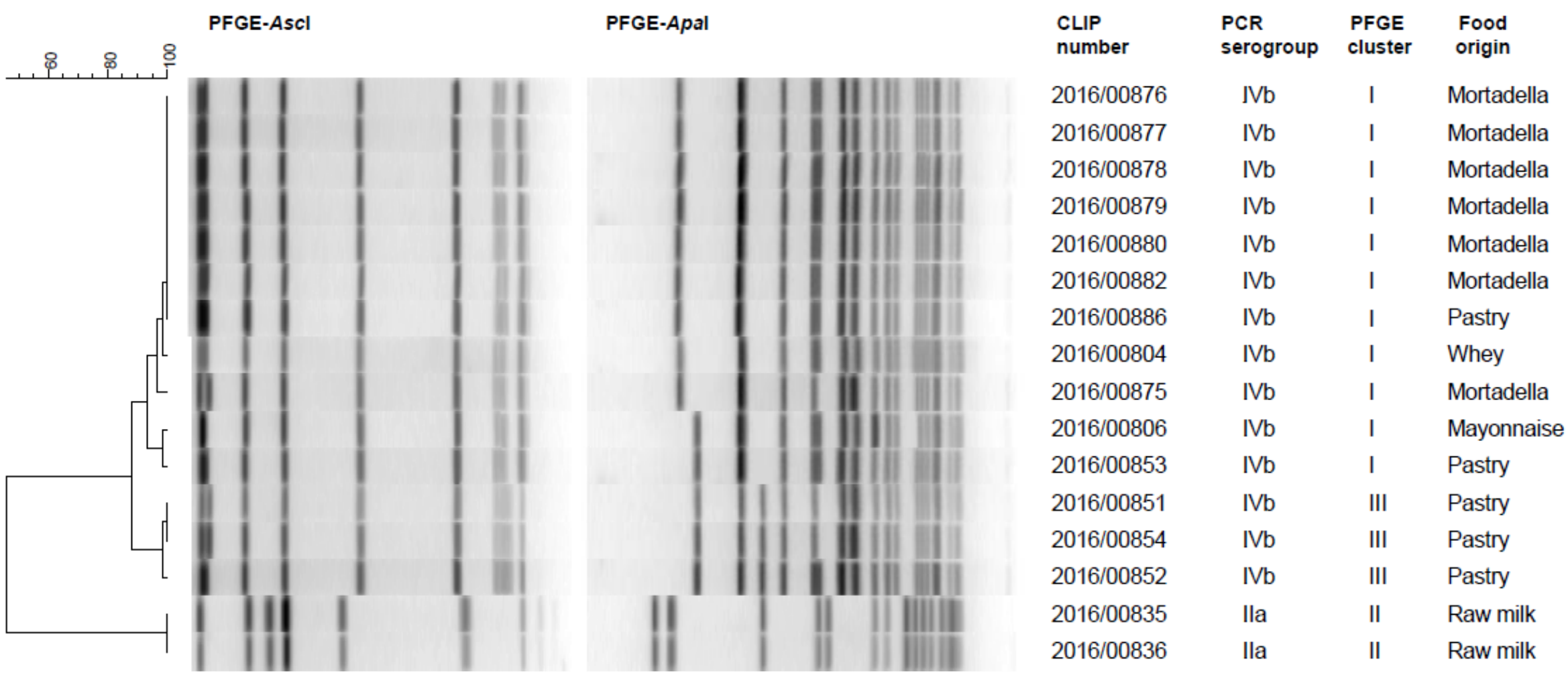

Figure 1. Unweighted pair group method with arithmetic mean (UPGMA) dendrogram based on Pulsed-field Gel Electrophoresis

(PFGE) profiles with Ascl and Apal endonuclease enzymes of $L$. monocytogenes isolated from food items. 


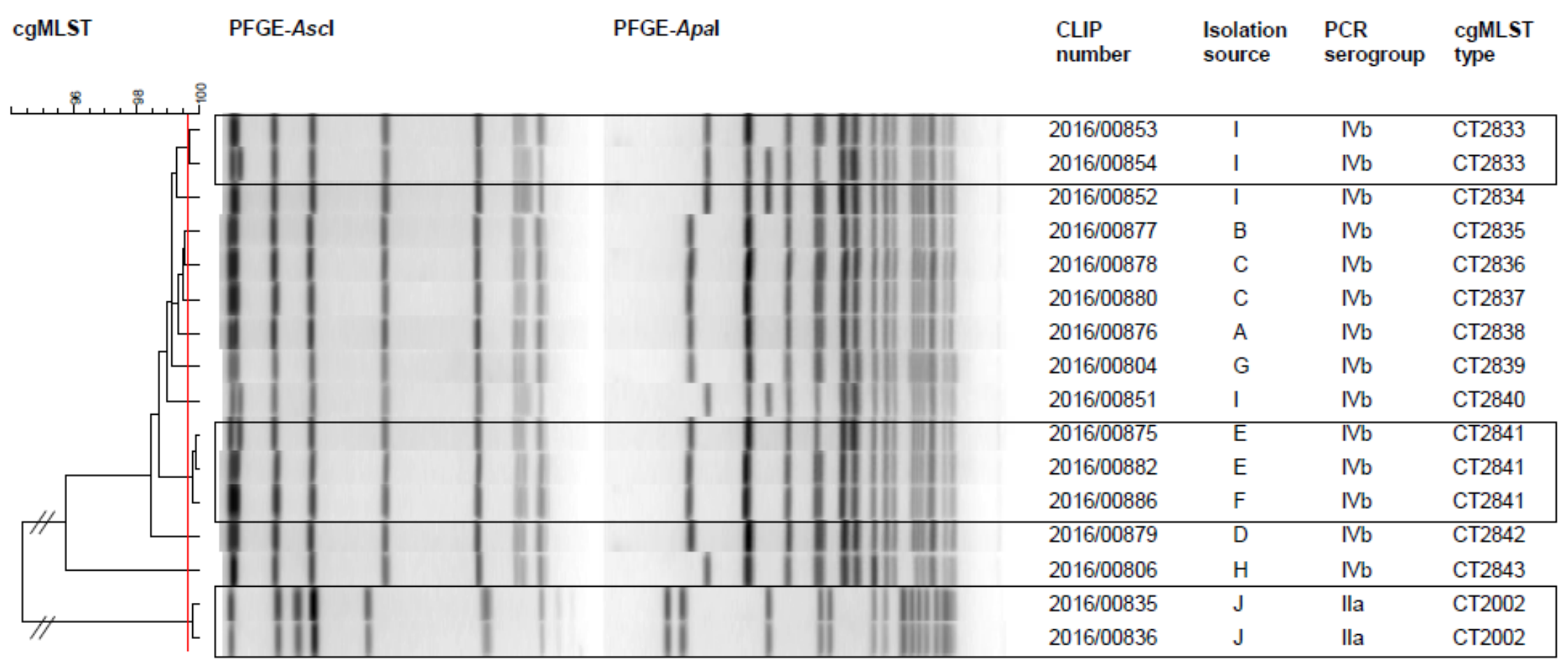

Figure 2. Single linkage dendrogram based on L. monocytogenes cgMLST profiles from genoserotype IVb. The vertical bar indicates the cgMLST type cut-off of $\mathbf{9 9 . 6 0 0 \%}$ (Moura et al., 2016). Horizontal boxes highlight clusters of isolates belonging to the same cgMLST type. 